\title{
Editorial
}

\section{Corrective Surgery of Tetralogy of Fallot}

\section{The Right Ventricular Outflow Obstruction and Its Relief}

\author{
Ken-ichi Asano, M. D.*
}

1 ORE than 80 per cent of patients with congenital cyanosis who survivBlalock-Taussing's operation as the palliative surgery still hold the clinical importance, but it cannot be accepted that there are some drawbacks especially in the duration of operative effects. Although the corrective surgery of the tetralogy of Fallot has been challenged since 10 years ago, it is still rather difficult to keep the constant and satisfactory surgical results. It is not with exaggeration to say that the conquest of this difficulty is even to tide over one side of barrier against the development of the cardiac surgery. The purpose of this editorial is to describe our preliminary observations in the recent study of the hemodynamics and our surgical technique for relief of the outflow obstruction in the tetralogy of Fallot.

The relationship between the mortality of the corrective surgery and the degree of the right ventricular outflow obstruction in the tetralogy of Fallot

The mortality of the corrective surgery is reported from 0 to 34 per cent in the recent literature as shown in Table $1 .{ }^{1-9)}$ But today, the mortality is reduced from 20 to 10 per cent, if the miserable results in the past are excluded. The lowest line in the table is our results.

Such rather high mortality may be attributable to the severity of this anomaly, the age of the patient and the surgical technique. Of these factors, many authors reported the high mortality in patients under 5 years of age, and it is recommended usually for children under 5 years of age to be treated primarily by the safer method, that is, Blalock-Taussig's operation in a serious case, or to be left in a mild case (Table II).

The clinical severity is usually classified into 4 groups, ${ }^{1), 31,5), 6)}$ that is, acyanotic, mild, moderate and severe groups. The clinical severity is much

* Professor, Department of Thoracic and Cardiovascular Surgery, Faculty of Medicine, University of Nigata, Niigata. 
Table I. Hospital Mortality Reported in the Recent Literature

\begin{tabular}{|c|c|c|}
\hline $1964-1966$ & Number of Patients & Mortality $(\%)$ \\
\hline Kirklin et al. ${ }^{1)}$ & 337 & 11 \\
\hline Zerbini et al. ${ }^{2)}$ & 274 & 18.6 \\
\hline Zenker, Klinner et al. ${ }^{3)}$ & 216 & 24 \\
\hline Leachman, Cooley et al.4 & 203 & 15 \\
\hline Dubost et al.5) & 185 & 26 \\
\hline Derra et $a l^{63}$ & 167 & 34 \\
\hline Wolf, Taussing et al.7) & 146 & 31 \\
\hline Soulie et al. ${ }^{83}$ & 63 & 30 \\
\hline Shumway et al.9) & 44 & 0 \\
\hline Author & 28 & 14.3 \\
\hline
\end{tabular}

Table II. Effect of $\Lambda$ ge on Hospital Mortality (\%)

\begin{tabular}{l|c|c|c|c|c}
\hline & Under 5 yrs. & $5-10$ yrs. & $11-15$ yrs. & $16-20$ yrs. & Over 20 yrs \\
\hline Kirklin et al. & 19 & \multicolumn{2}{|c|}{11} & 12 \\
\hline Wolf et al. & 60 & 27 & \multicolumn{2}{|c|}{36} & 15 \\
\hline Zerbini et al. & 33.3 & 10.1 & 6.2 & 4.8 & 52.6 \\
\hline Zenker et al. & - & 26.7 & & 22.9 & 21.7 \\
\hline Dubost et al. & 50 & 35 & 19 & 13 & 13 \\
\hline Author & - & 23 & 0 & & \\
\hline
\end{tabular}

Table III. Effect of Clinical Severity on Hospital Mortality (\%)

\begin{tabular}{c|c|c|c|c}
\hline Classification & Kirklin et al. $^{1)}$ & Zenker et al. ${ }^{37}$ & Dubost et al. & Derra et al. ${ }^{5)}$ \\
\hline I. Acyanotic & 0 & 0 & 5 & 0 \\
\hline II. Mild & 0 & 13 & 22 & 11 \\
\hline III. Moderate & 2.6 & 20.2 & 41 & 13 \\
\hline IV. Severe & 15.5 & 40.3 & 24 & 27 \\
\hline Number of Cases & 337 & 216 & 185 & 90
\end{tabular}

influenced by the anatomical features of the outflow tract, including the pulmonary trunk. There is the tendency that the predominant infundibular stenosis is found in milder groups and the predominant valvular stenosis with hypoplastic pulmonary trunk in severer groups, and the anatomical status is 


\begin{tabular}{c|c|c|c}
\hline Type of Obstruction & No. Pats. & Death & Mortality (\%) \\
\hline I. Localized Stenosis & 9 & 0 & 0 \\
\hline II. Intermediate Stenosis & 8 & 0 & 0 \\
\hline III. Diffuse Stenosis & 11 & 4 & 36
\end{tabular}
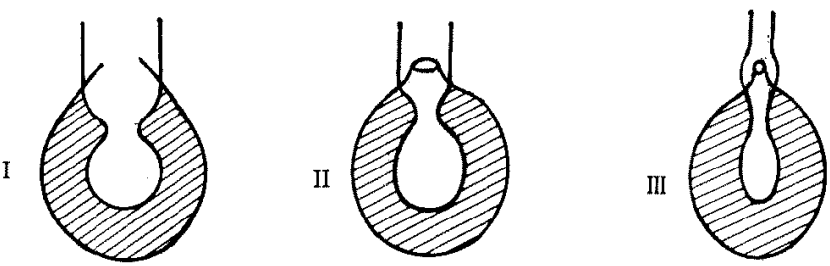

Fig. 1. Effect of the outflow obstructions on the mortality,

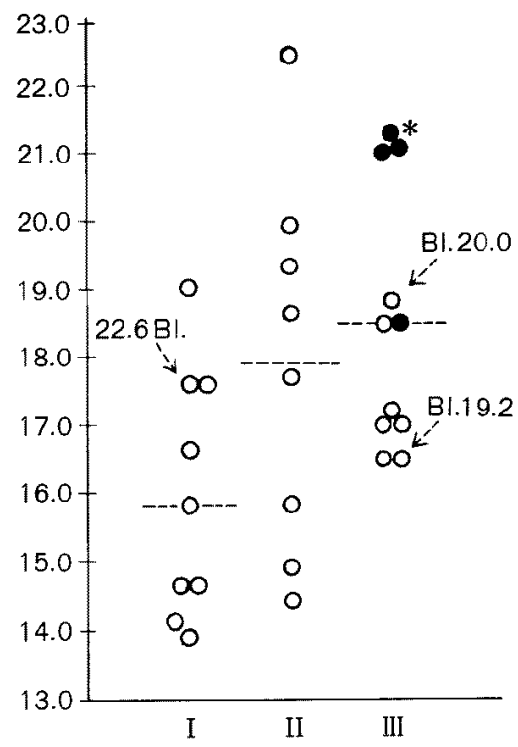

Fig. 2. The type of stenosis and polycythemia expressed by hemoglobin (Gm./100 ml.).

Open circle is the survival and closed circle is the dead. Dotted line is the average value of the respective group, B1 indicates the case with previous Blalock-Taussig's operation and the number is the value of hemoglobin (Gm./100 ml.) before anastomosis. * This case died 4 months after surgcry due to the postoperative bacterial endocarditis.

closely related to the mortality of the corrective surgery (Table III).

We classify the outflow obstruction into 3 types. Type $\mathbf{I}$ is the localized stenosis (infundibular stenosis), type II is the intermediate stenosis and type III is the diffuse stenosis (infundibulovalvular stenosis with the marked hypoplastic pulmonary trunk). Type III is considered to correspond to abovementioned severe group, and the operative mortality of type III was the highest 
in our series. Fig. 1 and 2 show the relationships between the type of the outflow obstruction and the operative mortality and the clinical severity expressed by polycythemia. Therefore, the morphology and the degree of the outflow obstruction are the most important factor influencing the operative result.

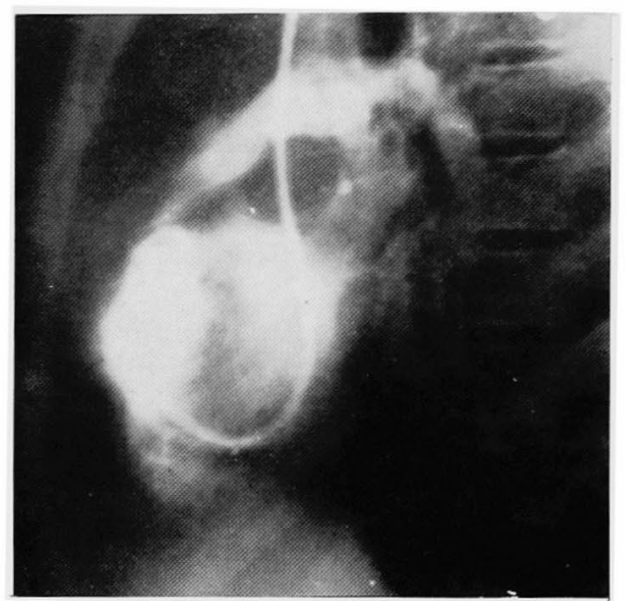

Fig. 3. Preoperative angiocardiogram of type III stenosis. The ratio of PA/AO diamter was 0.56 .

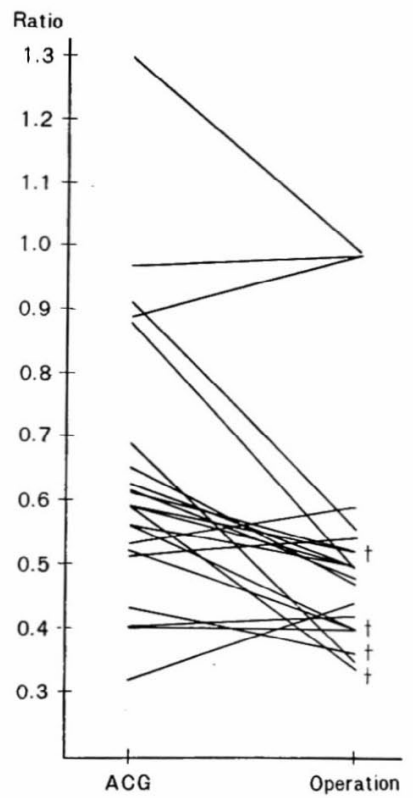

Fig. 4. The ratios of $\mathrm{PA} / \mathrm{AO}$ diameter in angiocardiogram and during operation. 
The hemodynamic effects of the beta-adrenergic blocking agent on the outflow tract

Presently the selective angiocardiography is routinely performed to obtain the details of the outflow obstruction preoperatively. Comparing with the preoperative angiocardiograms and the intraoperative findings, it might be experienced that both findings do not frequently coincide with each other, although Smith $^{10}$ described that a good agreement had been found between radiological and surgical assessments. Moreover, the trouble is that the calibre of the pulmonary trunk at surgery is often smaller both absolutely and in the ratio of $\mathrm{PA} / \mathrm{AO}$ diameter than that in the preoperative angiocardiograms. For example, Fig. 3 showed the preoperative outflow tract of one of our cases, and the intraoperative measurement revealed that the outside diameter of the ascending aorta was $33 \mathrm{~mm}$. and that of the pulmonary trunk just distal to the valve was $13 \mathrm{~mm}$. and the pulmonary trunk was unexpectedly hypoplastic. Fig. 4 shows the relationship between the ratios of $\mathrm{PA} / \mathrm{AO}$ diameter in the preoperative angiocardiogram and that dircctly mcasured during operation.

On the other hand, it has been recently reported that the systolic pressure gradients between the left ventricle and the aorta in the hypertrophic subaortic stenosis, tends to be increased by the administration of the betaadrenergic stimulating agent and to be reduced by that of the beta-adrenergic blocking agent. ${ }^{11)}$ Singh $^{12)}$ and Cumming ${ }^{13)}$ found in patients of the tetralogy of Fallot that beta-adrenergic stimulation produced anoxic spells and contrarily beta-adrenergic inhibition prevented or relieved the attacks. In addition, Cumming revealed the effect of the beta-adrenergic blockade on the hemodynamics and the angiocardiographic findings, and its efficiency in the medical treatment. Moreover, Pearse ${ }^{\mathbf{1 4})}$ demonstrated electron-microscopically the proliferation of sympathetic nerves (sympathosis) in the obstructive
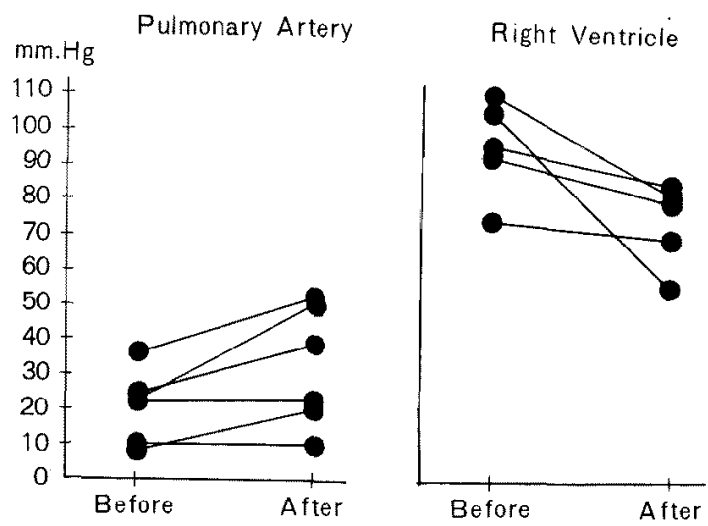

Fig. 5. Changes of intracardiac systolic pressures after administration of Inderal. 
hypertrophic myocardium of both above-mentioned diseases.

We have recently been studying the hemodynamic changes after the administration of the beta-adrenergic blockade and trying to interpret the response against this agent in relation to the type of the outflow obstruction.

Method and materials - 0.5 to $0.25 \mathrm{mg}$. per $\mathrm{Kg}$. of body weight of Inderal as the beta-adrenergic blockade was administered by instillation after exposure of the heart in 8 cases. Before and after the injection, systemic, pulmonary and right ventricular pressures were recorded with the electromanometer in 6 cases of them, and the oxygen saturation of the blood sources from the systemic artery, the pulmonary artery and both atria was measured with the oximeter in all.

Results - The systemic blood pressure fell moderately in all cases. However, the pulmonary arterial pressure rose in 4 cases, despite the fall of right ventricular pressure. Consequently, the systolic pressurc gradient between the right ventricle and the pulmonary artery decreased (Fig. 5). Oxygen saturation of the systemic arterial blood increased in 3 cases, but not in 5 cases (Fig. 6).

It might be postulated based on these preliminary observations as follows :

1. The beta-adrenergic blocking agent decreases the right-to-left shunt, raising pulmonary blood flow and increased the oxygen saturation of the systemic arterial blood probably due to the elimination of muscle tonus of the hypertrophied infundibulum. But, this response is obscure in cases with severe valvular stenosis or tight infundibular stenosis.

2. It seems possible to classify preoperatively the outflow obstruction of the tetralogy of Fallot into the spastic infundibular stenosis and the tight
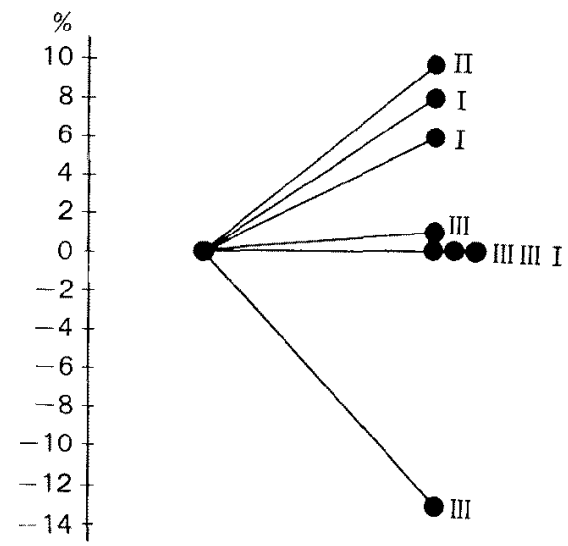

Fig. 6. Effect of Inderal on oxygen saturation of systemic arterial blood, change in per cent of preadministration value. I, II, III indicate types of stenosis. 
stenosis, including either valvular or infundibular stenosis by the intravenous administration of Inderal. Although it is generally difficult to explain the anatomical status by the hemodynamic findings, the more detailed and exact diagnosis may, at least, be made with the Inderal test in addition to the angiocardiographic study.

3. The beta-adrenergic blocking agent seems to be of definite value in the acute anoxic attack and to dispense with or postpone the emergency operation in some cyanotic infants.

Some problems in the surgical relief of the outflow obstruction

A close correlation between the status of the outflow obstruction and the clinical severity, does indicate that the degree of surgical relief of the obstruction is the most influential factor upon the operative mortality. Kirklin ${ }^{1)}$ has emphasized since early that RV/LV systolic pressure ratio under $0.6 \mathrm{im}$ mediately after repair was preferable to the operative prognosis and the hospital mortality was high in the case with the ratio over 0.75 . Griffith ${ }^{15)}$ described as the criteria of satisfactory relief of the obstruction the systolic pressure gradient between the right ventricle and the pulmonary artery to be under 40 $\mathrm{mm} . \mathrm{Hg}$. Dubost ${ }^{4)}$ reported that the mortality was 10 per cent in the group of $\mathrm{RV} / \mathrm{LV}$ ratio under $0.5,30$ per cent in the group of the ratio between 0.7 and 0.5 and 42 per cent in the group of the ratio over 0.7 . It is commonly agreed that the severe residual stenosis might most frequently dominate the poor operative results.

On the other hand, Gerbode ${ }^{16)}$ emphasized the approach to the outflow obstruction through the transverse right ventriculotomy to preserve the ventricular function for the previously used longitudinal right ventriculotomy. Now this approach is generally accepted in either the tetralogy or the ventricular septal defect and if necessary, an outflow patch is placed across the pulmonary valvular ring with the additional incision. Recently the indication of the outflow patch to relieve the severe obstruction has invited a good deal of comment about its necessity.

Kirklin ${ }^{11}$ described that patches had been used less frequently in more recent operations because the reduction in use of patches had not been accompanied by a significant increase in average $\mathrm{RV} / \mathrm{LV}$ systolic pressure ratio after repair, and the mortality of patients with patch was 19 per cent and that of patients without patch was 7 per cent. Zerbini, ${ }^{21}$ too, said the same opinion in the recent report. Wolf's results ${ }^{7)}$ revealed 42 per cent of mortality in patients with patch and 24 per cent in patients without patch.

However, contrarily, Klinner, ${ }^{17)}$ Shumway ${ }^{9)}$ and Dubost ${ }^{5)}$ reported to use an outflow patch more frequently from 42 to 58 per cent of all patients, 


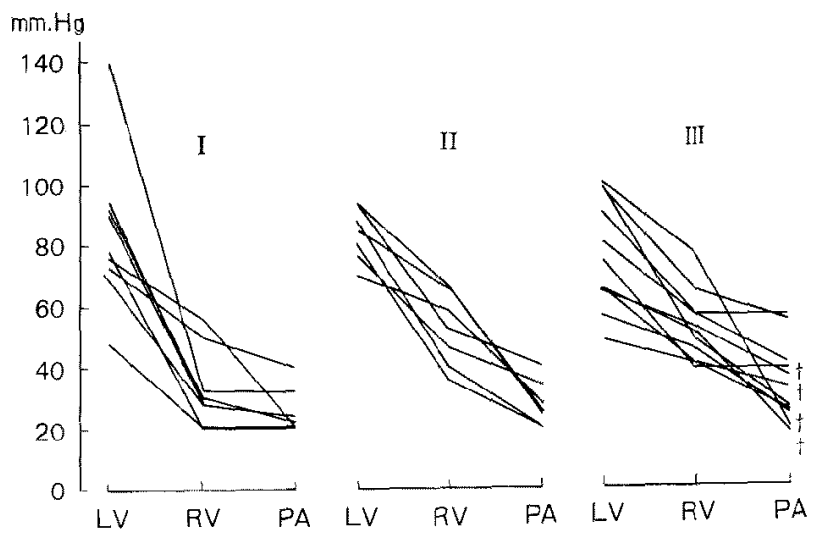

Fig. 7. The type of stenosis and in racardiac pressures immediately after repair.
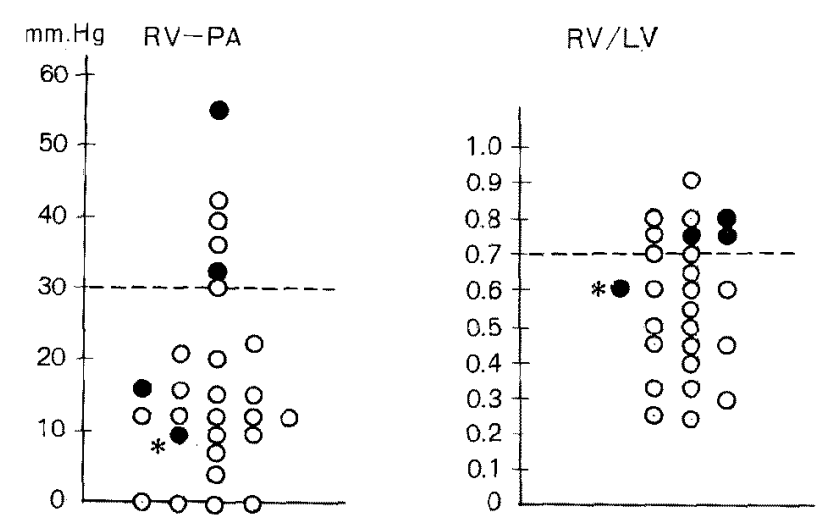

Fig. 8. The relationship between the degree of relief of the outflow obstruction and the mortality.

* 'This case died 4 months after surgery due to the postoperative bacterial endocarditis. Open circle is the survival and closed circle is the dead.

and Shumway experienced no mortality in patients either with or without patch. The author thinks that the indication of patch and the mortality of patients with patch seem to depend upon the particular surgical techniques and the severity of the condition, and it is the most important to relieve the obstruction by any means.

The pressure measurements and the operative results with regard to the approach of the outflow obstruction in our series are shown in Figs. 7 and 8. We have experienced that RV/LV systolic pressure ratio under 0.7 and RV-PA systolic pressure gradient under $30 \mathrm{~mm}$. $\mathrm{Hg}$ immediately after repair were preferable to the operative results. Based on our experiences, the approach through the transverse ventriculotomy combined with the additional ventricular incision to insert a patch resulted in the highest mortality, and the 


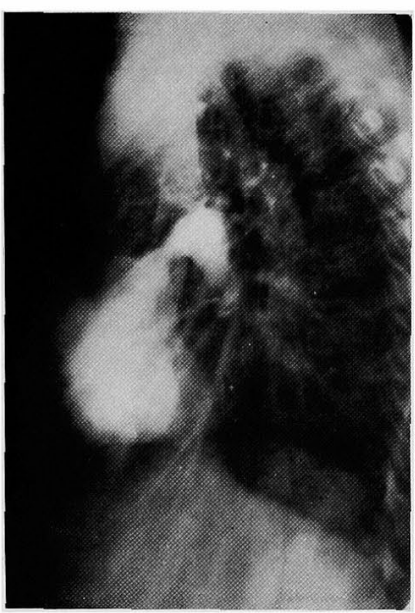

Fig. 9. Preoperative angiocardiogram of type III stenosis. The ratio of $\mathrm{PA} / \mathrm{AO}$ diameter was 0.32 .

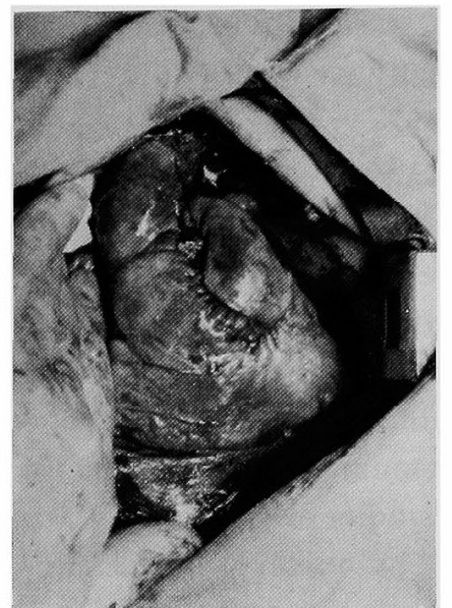

Fig. 10. Operative findings of the case of Fig. 9. Note the markedly transfigured pulmonary artery.

author considers about this approach as follows:

1. This approach is the inverted $T$ shape and seems to suppress the right ventricular function postoperatively more than the transverse ventriculotomy only.

2. The cross point of T-figure tends to be a blind spot for relief of the obstruction.

Therefore, we now make it a rule to treat the outflow obstruction of type I and II by the transverse ventriculotomy, and in the type III stenosis, to insert a large one-layer pericardial patch to the entire length of the longitudinal incision from the pulmonary bifurcation to the right ventricular outflow, if necessary. This method is undoubtedly inferior to the isolated transverse ventriculotomy as a meaning of preserving the ventricular function, but leaves no blind spot for relief of the obstruction. Figs. 9 and 10 are the preoperative angiocardiogram and the operative findings of one of such cases and the marked transfigured pulmonary trunk is demonstrated. Postoperative pressure measurements revealed of course the complete elimination of the obstruction and the postoperative courses were very smooth. However, if it is not preferable to incise the right ventricle longitudinally in the patient whose major branch of the right coronary artery is large and crosses over the outflow tract, the T-shaped incision is inevitably indicated. In such case the additional longitudinal pulmonary artery incision may end just beneath the pulmonary valvular ring.

Now there are still 2 more problems in use of the outflow patch, that is, the influence of the consequent pulmonary insufficiency on the right heart 
function and the late death. All patients except one are alive and well in our series, and have not any difference comparing with patients without pulmonary insufficiency. One patient had been suffered from the bacterial endocarditis postoperatively, then the closed septal defect was reopened and died due to sepsis and cardiac failure 4 months after surgery.

There have been many articles in the literature about the experimentally produced pulmonary insufficiency and the congenital isolated pulmonary insufficiency, discussing whether to be benign or not for the heart function and life. ${ }^{18)}$ But we can hardly discover any decisive comment about the postoperative pulmonary insufficiency of the tetralogy. Recently Shah ${ }^{19}$ reported on the basis of studies of patients following the corrective surgery that despite the presence of pulmonary insufficiency, borderline cardiac enlargement, complete right bundle branch block, and a healed ventriculotomy, the functional capacity of the heart expressed by exercise and isoproterenol-induction tests was well retained. Klinner ${ }^{17}$ ) successfully tried to bypass the right ventricle to the distal pulmonary artery with a Teflon-graft even in the case of the tetralogy of Fallot with the atretic puimonary artery. It must be recognized that we can not always surgically treat every type of the tetralogy, unless such technique as above-described can be fluently applied, if necessary.

\section{SUMMARY}

Among 28 patients with corrective surgery of the tetralogy of Fallot, 3 patients died early postoperatively and 1 died 4 months after surgery. Early deaths were all due to incomplete relief of the obstruction of the right ventricular outflow tract.

A preliminary observation of the hemodynamic changes after betaadrenergic inhibition was tried in order to classify the type of the obstruction and revealed some interesting facts.

The author discussed the relationship between the type of the obstruction and the surgical mortality, and that between some operative techniques and the degree of surgical relief of the obstruction, and emphasized that it was the most important to endeavour to relieve the obstruction as completely as possible for improvement of the surgical result.

\section{REFERENCES}

1. Kirklin, J. W., Wallace, R. B., McGoon, D. C., and DuShane, J. W. : Ann. Surg, 162 : 578, 1965.

2. Zerbini, E. J., Macruz, R., Bittencourt, D., Jatene, A., and Filho, C. M. C.: J. Cardiovas. Surg. $7: 209,1966$. 
3. Zenker, R., Klinner, W., and Sebening, F.: Zentralblatt Chir. 44 : 1635, 1964.

4. Leachman, R. D., Hallman, G. L., and Cooley, D. A.: Girculation 32: 65, 1965.

5. Dubost, G., Blondeau, P., D'Allaines, C., Piwnica, A., and Guilmet, D.: Arch. Mal. du Coeur 58: 1552, 1965.

6. Derra, E. and Loehr, B. : Zentralblatt Chir. 10:321, 1964.

7. Wolf, M. D., Landtman, B., Neil, C. A., and Taussig, H. B. : Circulation 31 : 385, 1965.

8. Soulie, P., Corone, P., Lainee, R., and Vernant, P. : Arch. Mal. du Coeur 58: 1575, 1965.

9. Shumway, N.E., Lower, R.R., Hurley, E.J., and Pillsbury, R.C.: Girculation 31 \& 32, Suppl. $1: 57,1965$.

10. Smith, D. R., Effat, H., Jamed, M. A., and Omeri, M. A. : Brit. Heart J. 27 : 604, 1965.

11. Harrison, D. C., Braunwald, E., Glick, G., Mason, D. T., Chidsey, C. A., and Ross, J., Jr. : Circulation 29 : 84, 1964.

12. Singh, S. P. and Gotsman, M. S. : Brit. Heart J. $28: 98,1966$.

13. Cumming, G. R. and Carr, W.: Lancet 1: 519, 1966.

14. Pearse, A. G. E. : The histochemistry and electron microscopy of obstructive cardiomyopathy, in CIBA Foundation Symposium: Cardiomyopathies, p. 132, 1964. (quoted from-Bentall, H. H. \& Morrow, A. G. : J. Thorac. Cardiovas. Surg. 51 : 49, 1966.)

15. Griffith, S. P. and Malm, J. R. : Prog. Cardiovas. Dis. 8 : 64, 1965.

16. Gerbode, F. and Kerth, W.J.: Ann. Surg. 158: 975, 1963.

17. Klinner, W. and Zenker, R.: Surg. 57: 353, 1965.

18. Gollins, N. P. : Surg. 52: 942, 1962.

19. Shah, P. and Kidd, L.: J. Thorac. Cardiovas. Surg. 52 : 138, 1966. 